www.jmscr.igmpublication.org

Impact Factor 5.84

Index Copernicus Value: 83.27

ISSN (e)-2347-176x ISSN (p) 2455-0450

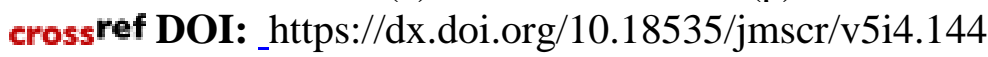

Journal Of Medical Science And Clinical Research

\title{
A Study on Role of Neo adjuvant Chemotherapy in Locally Advanced Carcinoma of Breast
}

\section{Dr Vinaya K Ambore ${ }^{1}$, Dr Mohammed Siddique J A², Dr Ali Zaid Anwar Dr Tejashree $\mathbf{S}$ Borade ${ }^{4}$}

${ }^{1}$ Associate Professor and unit head, Department of General Surgery, Grants Government Medical College and JJ Groups of Hospital, Mumbai, Maharashtra

Email:vinaya.ambore@gmail.com

${ }^{2}$ Assistant Professor, Department of General Surgery, Grants Government Medical College and JJ Groups of Hospital, Mumbai, Maharashtra

Email: hashmisiddique2@gmail.com

${ }^{3}$ Junior Resident, Department of General Surgery, Grants Government Medical College and JJ Groups of Hospital, Mumbai, Maharashtra

Email: zaidanwar08@gmail.com

${ }^{4}$ Senior Resident, Department of General Surgery, Grants Government Medical College and JJ Groups of Hospital, Mumbai, Maharashtra

Email: tejashreesiya333@gmail.com

\begin{abstract}
Aims and Objectives: To evaluate the role of Neo adjuvant Chemotherapy in Locally Advanced Carcinoma of Breast along with its incidence, to study different regimens and effect of each cycle on tumour and to study the common side effects

Material and Methods: A case control study was done having Locally Advanced Breast Cancer in a tertiary care hospital, medical record of patients from November 2013 to November 2015 was accessed in a total of 42 patients.

Results: It showed that the most common age group of incidence was 45-54 years and 88.6\% were multiparous. Upper outer quadrant was involved in most cases $54.5 \%$ followed by lower quadrant 13.6\%. 75 $\%$ of cancers were found to be IDC NOS Type. Most common regimen used was FAC leading to most common complication Nausea followed by CMF whose most common complication was alopecia followed by AC were both nausea and alopecia were common. There was a significant decrease in tumour size after chemotherapy $(6.9+/-1.12$ to $3.62+/-1.01, p$ value <0.05).MRM was the most common surgery done followed by simple mastectomy. Overall, the CMF regimen proves more effective than any other regimen as it provides good resect ability of the tumour as compared to other regimen.

Conclusion: There was significant decrease in tumour size after NACT making a select group of patient suitable for conservative surgeries but long term cure rates are still $<50 \%$.

Keywords: Neo adjuvant chemotherapy, Locally Advanced Breast Cancer.
\end{abstract}




\section{INTRODUCTION}

The incidence of breast cancer is on the rise pushing cervical cancer on second spot, being one in 22 women. The term Locally Advanced Breast Carcinoma (LABC) is used to describe a breast cancer that has progressed locally but has not yet spread outside the breast \& local lymph nodes. Locally Advanced Breast Carcinoma accounts for 30-35 \% of all cases of carcinoma breast in India. The rise is being documented mainly in the metros but it can be safely said that many cases in rural India go unnoticed. LABC accounts for 30-35\% of all cases of breast cancer in India. LABC is defined as, the Tumour of size $>5 \mathrm{~cm}$, cancer that involves the skin or breast or underlying muscles/ rib,cancer that involves multiple lymph nodes ${ }^{1}$.

Neoadjuvant Chemotherapy is used to shrink the tumourand to destroy undetectable cancer cells in the body. Various regimens used areAC (Doxorubicin, Cyclophosphamide), CE (Cyclophosphamide, Epirubicin), CMF (Cyclophosphamide, Methotrexate, 5Fluorouracil), FAC (5- Fluorouracil, Doxorubicin, Cyclophosphamide), FEC (5- Fluorouracil, Epirubicin, Cyclophosphamide).

Our study was done to evaluate the outcome of neo-adjuvant chemotherapy in surgical cases that present with features of LABC, at a multispecialty tertiary care hospital in Mumbai.

\section{MATERIALS AND METHODS}

A case control study was done of LABC in a tertiary care hospital; medical record of patients from November 2013 to November 2015 was assessed in a total of 42 patients with inclusion criteria's being (1) All female patients presenting with features of LABC of breast of age group 2560 years (2) Those patients willing for study (3) Non-immunocompromised patients. Exclusion criteria's being (1) Patients with features of early breast carcinoma (2) Patients who did not complete the whole course of treatment (3) Inflammatory carcinoma of breast (4) immunocompromised patients. The various regimens used were studied along with their side effects to find the most appropriate regimen.

\section{RESULTS}

The incidence was found to be most common in the age group of 45-54 years. Upper outer quadrant was involved in most cases followed by lower quadrant. $75 \%$ of cancers were found to be IDC NOS Type. Most common regimen used was FAC leading to most common complication of nausea followed by $\mathrm{CMF}$ whose most common complication was alopecia.

Table 1: Concise Results of Our Study

\begin{tabular}{|c|c|c|c|}
\hline & & $\begin{array}{l}\text { FREQUE } \\
\text { NCY }\end{array}$ & $\begin{array}{c}\text { PERCENT } \\
\text { AGE }\end{array}$ \\
\hline \multirow[t]{4}{*}{ Age Groups } & $25-34$ & 3 & 7.14 \\
\hline & $35-44$ & 9 & 21.43 \\
\hline & $45-54$ & 21 & 50 \\
\hline & $55-65$ & 9 & 21.43 \\
\hline \multirow[t]{3}{*}{ Other Factors } & Menopause & 23 & 52.3 \\
\hline & $\begin{array}{c}\text { Breast } \\
\text { Feeding }\end{array}$ & 39 & 88.6 \\
\hline & $\begin{array}{l}\text { Family } \\
\text { History }\end{array}$ & 3 & 6.8 \\
\hline \multirow[t]{2}{*}{ Parity } & Multiparous & 39 & 88.6 \\
\hline & Nulliparous & 3 & 6.8 \\
\hline \multirow{5}{*}{$\begin{array}{ll}\text { Breast } & \text { Quadrant } \\
\text { Involved } & \end{array}$} & Central & 4 & 9.1 \\
\hline & Lower Inner & 6 & 13.6 \\
\hline & Lower Outer & 3 & 6.8 \\
\hline & Upper Inner & 5 & 11.4 \\
\hline & Upper Outer & 24 & 54.5 \\
\hline \multirow{3}{*}{$\begin{array}{l}\text { HISTOPATHOLO } \\
\text { GICAL } \\
\text { GRADING }\end{array}$} & IDC NOS & 33 & 75 \\
\hline & LOBULAR & 3 & 6.8 \\
\hline & $\begin{array}{c}\text { MEDULAR } \\
\mathrm{Y}\end{array}$ & 6 & 13.6 \\
\hline \multirow{5}{*}{\begin{tabular}{ll}
\multicolumn{2}{l}{ CHEMOTHERAP } \\
Y & REGIMEN \\
USED &
\end{tabular}} & $\mathrm{AC}$ & 9 & 20.5 \\
\hline & $\mathrm{CE}$ & 4 & 9.1 \\
\hline & CMF & 9 & 20.5 \\
\hline & FAC & 17 & 38.6 \\
\hline & FEC & 3 & 6.8 \\
\hline \multirow[t]{4}{*}{$\begin{array}{l}\text { SURGERIES } \\
\text { PERFORMED }\end{array}$} & $\begin{array}{c}\text { MASTECT } \\
\text { OMY }\end{array}$ & 4 & 9.1 \\
\hline & MRM & 26 & 59.1 \\
\hline & $\begin{array}{c}\text { SIMPLE } \\
\text { MASTECT } \\
\text { OMY } \\
\end{array}$ & 7 & 15.9 \\
\hline & WLE+BCT & 5 & 11.4 \\
\hline
\end{tabular}

Table no 2: Size of tumour before and after Neo adjuvant Chemotherapy

\begin{tabular}{|l|c|c|c|}
\hline Size of tumour & N & Mean \pm SD & P value \\
\hline Pre-treatment size & 42 & $6.9 \pm 1.12$ & \\
\cline { 1 - 3 } Post-treatment size & 42 & $3.62 \pm 1,01$ & \multirow{2}{*}{$<0.05(\mathrm{~S})$} \\
\hline
\end{tabular}


There was significant decrease in tumour size after Neo adjunct Chemotherapy

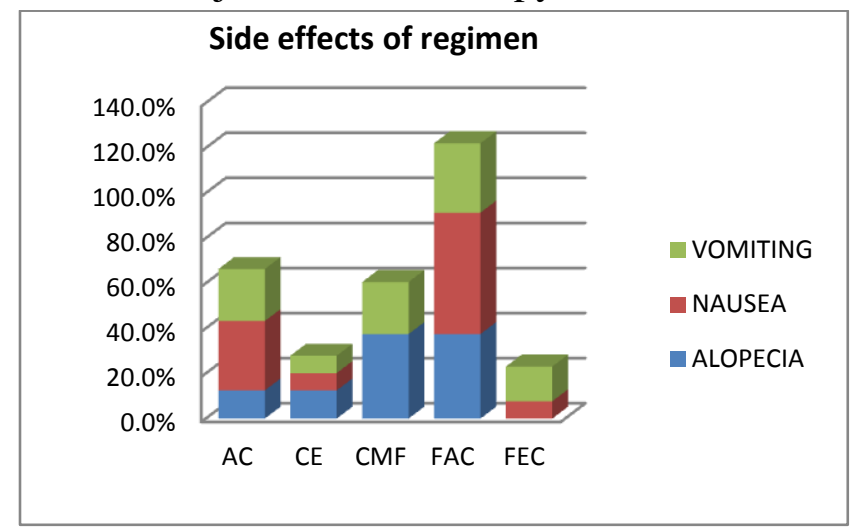

Chart 1: Different Side effects in Different Chemotherapy regimen

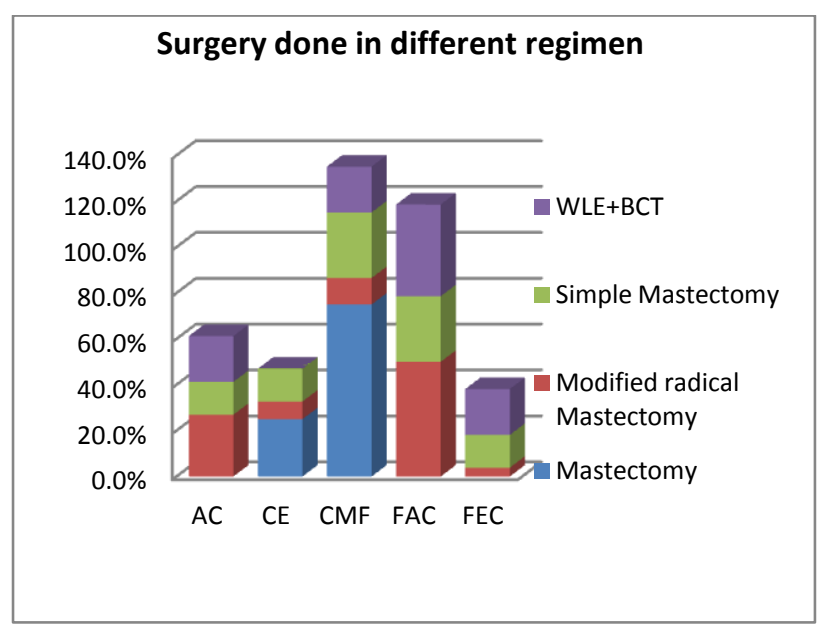

Chart 2: Surgeries Done In Different Chemotherapy Regimen

\section{DISCUSSION}

Breast cancer is the most common cancer in women and the leading cause of cancer death among females, accounting for $23 \%$ of the total cancer cases and $14 \%$ of cancer deaths ${ }^{2}$. Neo adjuvant chemotherapy in breast cancer treatment defines the use of cytotoxic chemotherapy before any local treatment, either surgery or radiotherapy. Although other terms such as 'primary', 'preoperative', 'induction', 'upfront' or 'initial' are perhaps more accurate descriptions, it was decided during the 2003 Consensus Conference to retain the more commonly used term 'neoadjuvant'?

In present study, 45-54 years of age was the most commonage group (50\%) followed by 35-44 $(21.43 \%)$. Mean age was $46.95+/-8.29$ years. In study conducted by Uroos Fatima et $\mathrm{al}^{4}$, in 2014, the commonest age group was 41-50 years (34\%). Mean age of the patients seen in the five hospital based cancer registries for the period of 2004-06 was found to range from 46.4 years in Dibrugarh to 50.6 years in Chennai (ICMR, 2009). The incidence of breast cancer is still increasing which is likely due to change in reproductive factors as well as increased screening intensity. Breast cancer is strongly related to age as only $5 \%$ occur in $<40$ years of age 5 .

Menopause was achieved in $52.3 \%$ of patient in our study. While in the similar study conducted by Sabahattin Aslan et $\mathrm{al}^{6}, 47.1 \%$ were of postmenopausal status.39 cases out of 42 were found to be multiparous in our study and $6.8 \%$ patients were nulliparous. In the similar study by Agarwal Kapil et $\mathrm{al}^{7}, 4.9 \%$ were nulliparous. In present study, pain was present in $59.1 \%$, skin changes in $43.2 \%$, ulcer in $34.1 \%$.

It has been noted that women who have first degree relative with breast cancer have a risk of 23 times the normal population; the risk factor was increased if the relative was affected at an early age and /or had bilateral disease ${ }^{8}$.In present study only $6.8 \%$ revealed a postitive family history. In study conducted by Agarwal Kapil et $\mathrm{al}^{7}$, only $4.88 \%$ cases revealed a positive family history of breast cancer. Mothers of the study were affected in all of them.

Upper outer quadrant was involved commonly followed by lower inner quadrant. In the similar study conducted by Sabahattin Aslan et $\mathrm{al}^{6}$,upper outer quadrant was most commonly involved 64 $\%$ was most involved site.

In present study, Infiltrating Ductal Carcinoma, Not Otherwise Specified (IDC NOS) $75 \%$ was the most common. There was significant decrease in tumour size after neo adjuvant chemotherapy. The down staging of tumours occur in significant number of patients which made tumour operable. In study by Agarwal et $\mathrm{al}^{7}$, infiltrating ductal carcinoma contributes $87 \%$ and medullary carcinoma $8.13 \%$. 
In the present study FAC regimen was most commonly used (38.6\%) followed by CMF (20.5 $\%$ ) and (AC $20.5 \%$ ). In similar study by Sutima et $\mathrm{al}^{10}$, FAC was most common regimen used (47.6 \%) followed by AC (41.8\%). Modified Radical Mastectomy was most common surgery done $(59.1 \%)$ followed by Simple Mastectomy (15.9\%) and Wide Local Excision (11.4\%)in our study. In similar study by Deo et $\mathrm{al}^{11}$, Modified Radical Mastectomy was performed in $91.4 \%$. In present study, in FAC regimen, nausea was present in 7 cases alopecia in 6 cases and vomiting in 4 cases. In $9 \mathrm{CMF}$ regimen, nausea present in 0 cases, alopecia in 6 cases and vomiting in 3 cases. In $9 \mathrm{AC}$ regimen cases, nausea was present in 4 cases, alopecia in 2 cases and vomiting in 3 cases amongst study population. In our study it was seen that the CMF regimen increased the resectability of the tumour with relatively less side effects followed by FAC and AC.

\section{CONCLUSION}

Surgery has evolved from the era of Radical Mastectomy to Modified Radical Mastectomy to present era where Breast Conservative Therapy is being attempted. The Modified Radical Mastectomy still remains the standard of care in surgical management of Locally Advanced Breast Carcinoma. The role of Breast Conservative Therapy in Locally Advanced Breast Carcinoma is establishing slowly and recently concluded EORTC trial will hopefully resolve this issue.

\section{REFERENCES}

1. Olivotto IA, Chua B, Allan SJ, et al. Longterm survival of patients with supraclavicular metastases at diagnosis of breast cancer. J Clin Oncol 2003;21:851-4.

2. Jemal A, Bray F, Center MM, et al. Global cancer statistics. CA Cancer J Clin, 2011.

3. Schwartz GF, Hortobagyi GN. Proceedings of the consensus conference on neoadjuvant chemotherapy in carcinoma of the breast, 2004; 100:2512-32.

4. Uroos Fatima, Rana Sherwani, Tamkin Khan, Sufian Zaheer, Foetal AutopsyCategories and Causes of Death, J Clin Diagn Res, 2014 Oct: 8(10).

5. Anders CK, Johnson R, Litton $\mathrm{J}$, et al. Breast cancer before age 40 years. Semin Oncol 2009; 36:237-49.

6. Sabahattin Aslan, MD, Abdullah Çetin, MD, Breast cancer infiltration by cardiothoracic surgery, Can J Surg. 2009 Jun; 52(3): E66-E68.

7. Agrawal Kapil H1, Rajderkar SS2, Clinico-Epidemiological Profile Of Female Breast Cancers and Its Important Correlates: A Hospital Based Study, National Journal of Community Medicine Vol 3 Issue 2 April-June 2012; 316-20.

8. Skolnick MH. Systematic populationbased assessment of cancer risk in firstdegree relatives of cancer probands, J Natl Cancer Inst. 1994 Nov 2;86(21):16001608.

9. Graishar WJ, Tjulndin S, Davidson $\mathrm{N}$ et al. Phase III trial of nanoparticle albumin-bound paclitaxel compared with polyethylated castor oil-based paclitaxel in women with breast cancer. J Clin Oncol 2005; 23(31): 7794-80.

10. Sutima L, Norasate S, Krittiya K. Association between Pathological Complete Response and Outcome Following Neoadjuvant Chemotherapy in Locally Advanced Breast Cancer Patients, J Breast Cancer 2014 December; 17(4): 376-385.

11. Deo, S.V.S., Bhutani, M., Shukla, N. K.,et al, Randomized trial comparing neoadjuvant versus adjuvant chemotherapy in operable locally advanced breast cancer (T4b N0-2 M0).(2003), J. Surg. Oncol., 84: 192-197. 